\title{
EDQM-HC Combined Pharmaceutical Dose Form Terminology
}

National Cancer Institute

\section{Source}

National Cancer Institute. EDQM-HC Combined Pharmaceutical Dose Form Terminology.

NCI Thesaurus. Code C150104.

Terminology subset about single terms to describe two or more manufactured items that are intended to be combined in a specific way to produce a single pharmaceutical product, and which includes information on the manufactured dose form of each manufactured item and the administrable dose form of the pharmaceutical product. Note: in the example 'Powder and solvent for solution for injection', the medicinal product contains two manufactured items: (i) a powder for solution for injection, and (ii) a solvent; the pharmaceutical product that is prepared form the two manufactured items is a solution for injection; the combined pharmaceutical dose form for the medicinal product is therefore 'powder and solvent for solution for injection'. 